\title{
SYNTHESIS AND PROPERTIES OF METAL-COMPLEX CATALYSTS BASED ON OIL METALLOPORPHYRINS
}

\author{
Minira Aghahuseynova \\ Department of Chemistry and Technology of Inorganic Substances \\ Azerbaijan State Oil and Industry University \\ 20 Azadlig ave., Baku, Azerbaijan, AZ1010 \\ minira_baku@yahoo.com
}

\begin{abstract}
The study of the properties and use of natural metalloporphyrins in the development of new highly selective methods for the oxygenation of hydrocarbons at moderate temperatures is an urgent problem. The present work is devoted to the extraction of metalloporphyrins from oil residues and the creation on their basis of effective catalytic systems for the oxidation of alkenes. The separation of metalloporphyrins from oil residues was carried out using new bifunctional organic extractants having the nature of keto-alcohols and providing a greater degree of extraction of porphyrins in comparison with the known traditionally used extractants.

The results of a study of a number of new bifunctional organic reagents as extractants for the selective extraction of oil porphyrins from asphaltenes are presented, their spectral characteristics are studied, the dependence of the degree of extraction on the mass ratio of the extractant and the crude oil is revealed. The best results were obtained with a mass ratio of 1:30. The isolated mixture of metalloporphyrins is first subjected to demetallization with hydrochloric acid $(\mathrm{pH}=1-2)$, turning into a mixture of porphyrins, then, to obtain individual metal porphyrin complexes, the required transition metal ions are introduced into the porphyrin ring by treating the mixture with these metal salts. It was shown that the yield of synthesized oil porphyrins is $42-85 \%$, depending on the nature of the metal. The composition and structure of the synthesized oil metalloporphyrins containing iron, cobalt, nickel, manganese are established by modern methods of physico-chemical analysis. The catalytic properties of synthesized metalloporphyrins in the epoxidation of unsaturated alkenes have been investigated. Their dioxide adducts were obtained, and a mechanism was proposed for the oxidation of alkenes with the formation of oxinoid structures as a result of the decomposition of the oxygen complexes of metal porphyrins.
\end{abstract}

Keywords: oil metalloporphyrins, bifunctional extractants, asphaltenes, dioxide adducts, alkenes epoxidation.

DOI: $10.21303 / 2461-4262.2020 .001356$

\section{Introduction}

Interest in the porphyrin complexes of transition metals is growing due to the possibilities of their use as catalysts. In the literature [1-8] there are a sufficient number of works in which porphyrin complexes of transition metals are used as highly selective catalysts for the oxidation of hydrocarbons at moderate temperatures. Unlike metal complexes of organic compounds, porphyrin transition metal complexes can be considered as reconstructed natural enzymes. However, synthetic metalloporphyrins are practically insoluble in hydrocarbons and require the use of complex and expensive additional chemicals to homogenize the system. In this regard, natural metalloporphyrins are of particular interest, which, due to the presence of ether, ester fragments and alkyl radicals in the side branches, dissolve well in hydrocarbons.

Among natural metalloporphyrins, oil metalloporphyrin complexes are particularly interesting, which are distinguished by their simplicity of preparation and potential applications in petrochemical processes. Literature sources [9-15] provide information on their use for producing high-octane gasolines as antiknock agents to gasolines in the catalytic purification of natural gas from hydrogen sulfide and to create a membrane material for purifying natural gas from radon.

Oil metalloporphyrins are extremely interesting objects for creating supramolecular formations of various structures that exhibit unique photophysical and chemical properties $[1,16]$. This work is devoted to the current research topic of oil porphyrins, the interest in which has been steadily growing in the last two decades. The main task and merit of the presented work is its practical orientation, which is lacking in the vast majority of other works in this area carried out by well-known foreign and domestic teams.

It is no secret that the study of the applied properties of oil porphyrins is inhibited by the complexity of their isolation in pure form. The study is aimed at solving the problem of extracting oil porphyrins and studying their catalytic properties by the example of the epoxidation of olefins, well studied for synthetic metalloporphyrin catalysts. 
In this paper, let's present the results of studies on the synthesis and selection of effective extractants for the separation of metalloporphyrins from oil residues, the development of a method for the synthesis of catalytic systems based on extracted porphyrins, and their study as catalysts for the alkene oxidation reaction.

\section{Materials and methods of research}

The primary task to accomplish the purpose of this study was to extract natural metalloporphyrins from oil residues.

The heavy oil residues (asphaltenes) of the Azerbaijan oil of the Oil Rocks deposit, the characteristics of which are given in Table 1, were used as feedstock for the production of individual metal porphyrin complexes 1 [17].

\section{Table 1}

Characteristics of oil used in the Oil Rocks field

\begin{tabular}{|c|c|c|c|c|c|c|c|c|c|c|}
\hline \multirow[b]{2}{*}{ Field } & \multirow[b]{2}{*}{$\begin{array}{l}\text { Depth, } \\
\text { m }\end{array}$} & \multirow[b]{2}{*}{$\begin{array}{c}\text { Density, } \\
\mathrm{kg} / \mathrm{m}^{3}\end{array}$} & \multirow{2}{*}{$\begin{array}{c}\text { Viscosity } \\
\text { at } 20^{\circ} \mathrm{C} \\
\mathrm{mm} / \mathrm{s}^{2}\end{array}$} & \multirow{2}{*}{$\begin{array}{c}\text { Pour } \\
\text { tempera- } \\
\text { ture, }{ }^{\circ} \mathrm{C}\end{array}$} & \multicolumn{4}{|c|}{ Content, \% } & \multicolumn{2}{|c|}{ Fraction yield, \% } \\
\hline & & & & & Sulfur & Resin & Asphaltenes & $\begin{array}{c}\text { Paraffin } \\
\text { wax }\end{array}$ & To $200{ }^{\circ} \mathrm{C}$ & To $300{ }^{\circ} \mathrm{C}$ \\
\hline Oil Rocks & 2600 & $884-887$ & $20,8-29,8$ & -20 & $0,16-0,21$ & $10,0-12,0$ & $0,10-0,58$ & $0,30-1,0$ & $10-20$ & $42-52$ \\
\hline
\end{tabular}

\section{Extraction chromatographic isolation of metalloporphyrins from asphaltenes.}

To isolate the porphyrin concentrate from asphaltenes, gasoline was added to the oil sample in the flask (i. e. boiling fractions of $35-85^{\circ} \mathrm{C}$ ) to lower the viscosity. Then the extractant was poured into the flask and the mixture was carefully mixed. In this case, the oil sample in the solvent disintegrated into small droplets, thereby achieving good extraction. The mixture was heated with stirring at a temperature of $50-120^{\circ} \mathrm{C}$ for 2 hours. After this period, the mixture settled at room temperature for 5 hours. Then the extract was filtered, the filtrate in the presence of porphyrins had a pink color. It was noted that if porphyrin was absent or there were very few, the color was slightly green.

The solvent was completely removed in vacuum using a water-jet pump. The remainder in the flask in the form of a colored oil film was transferred with benzene into a measuring vessel $(35-40 \mathrm{ml})$ and diluted to a certain color depending on the content of porphyrin complexes, making sure that the initial optical density was not more than $0.6-0.8$. The measurements were carried out on a SPICORD UV-VİS and SF-26 spectrophotometer.

The contents of vanadyl- and nickel- porphyrins were determined spectrophotometrically.

$$
\begin{aligned}
& \mathrm{C}_{V P}=\left(4.76 \cdot V \cdot A_{568}\right) / \mathrm{m} \cdot \mathrm{l}, \\
& \mathrm{C}_{N P}=\left(3.15 \cdot V \cdot A_{528}\right) / \mathrm{m} \cdot \mathrm{l},
\end{aligned}
$$

where $\mathrm{C}_{V P}, \mathrm{C}_{N P}$ - respectively, the concentration of vanadyl and nickel porphyrins, $\mathrm{mg} / 100 \mathrm{~g}$ of oil; $V$ - volume of solvent, $\mathrm{cm}^{3} ; \mathrm{A}_{568}$ and $\mathrm{A}_{528}$ are optical densities at the maxima of the analytical absorption bands; $m$ - a sample of oil asphaltene, $\mathrm{g}, l$ - cell thickness.

Reference $A$ was taken from the baseline, for which the background absorption curve of resinous components was used. The concentration of vanadyl porphyrins in asphaltenes, determined according to UV spectroscopy, was $180-195 \mathrm{mg} / 100 \mathrm{~g}$. The degree of extraction of vanadyl porphyrins was calculated from their content in asphaltenes and in extracts.

The method of obtaining oxygen adduct.

$2.28 \mathrm{~g}$ of cobalt (II) oil porphyrin complex and $40 \mathrm{ml}$ of carbon tetrachloride were placed in a $100 \mathrm{ml}$ metal ampoule, the ampoule was connected to an oxygen cylinder under a pressure of 5.0 $\mathrm{MPa}$ and the rocker was turned on. The reaction was carried out at room temperature for 3 hours. The end of the reaction was established by stopping the absorption of oxygen. At the end of the reaction, the contents in a metal ampoule were cooled at normal pressure, and the precipitate 
formed was filtered through a glass filter. The obtained brown solid precipitate $1.52 \mathrm{~g}(62.3 \%)$ after washing with oil ether and drying at room temperature was analyzed using cobalt spectrophotometric method $[9,14]$. The cobalt content in the sample of the oxygen adduct determined by atomic absorption spectrometry [19] was $6.25 \%$.

The method of epoxidation of alkenes with a dioxid adduct.

$0.45 \mathrm{~g}$ of oxygen adduct and $35 \mathrm{~g}(0.5 \mathrm{~mol})$ of 1-pentene were placed in a metal ampoule and heated at $60{ }^{\circ} \mathrm{C}$ for 3 hours, then the reaction mixture was filtered using a glass filter, the filtrate was determined by GLC yield 1,2-oxidopentane, amounted to $65 \%$ (according to the olefin taken in the reaction).

Physico-chemical methods for the study of synthesized metalloporphyrin complexes.

IR spectra were recorded on a SPECORD-M80 spectrometer in the region of 4000-400 $\mathrm{cm}^{-1}$ in $\mathrm{KBr}$ tablets. Electronic spectra were recorded using UV/Vis SPICORD and SF 16 spectrophotometers. To determine the content of metals ( $\mathrm{Mn}, \mathrm{Fe}, \mathrm{Co}, \mathrm{Ni})$ in the isolated metalloporphyrins, the AAS-300 atomic absorption spectrometer, Perkin-Elmer, was used. Gas-liquid chromatographic analyzes were carried out on an LKhM-8MD chromatograph, column sizes $5 \times 2.5 \mathrm{~m}$, carrier helium gas, absorbent PEG-1000. The obtained epoxy compounds were identified by GLC and specific chemical transformations characterizing the oxirane ring.

\section{Research results}

To isolate a mixture of metalloporphyrins from oil residues, the selective extraction method is usually used in petrochemistry using an ethanol-acetone mixture as an extractant with a degree of isolation of porphyrins in the amount of 50-60\%, as well as a method using dimethylformamide (DMF) with a significantly higher degree of isolation [18-20], although, along with metalloporphyrins, various classes of organic substances are extracted, which is a drawback of this method.

In order to increase the selectivity and efficiency of the extraction of metal porphyrins from oil for extraction chromatographic isolation, new bifunctional organic extractants were synthesized and proposed for use: 2-methyl-pentanon-4-ol-2 (I), 2,2,5-trimethylheptanone-3-ol-5 (II), 2-hydroxycyclohexanone (III).

Table 2 shows some characteristics of extractants I-III.

Table 2

Some characteristics of synthesized by extractants I-III used for the selective extraction of oil metalloporphyrins

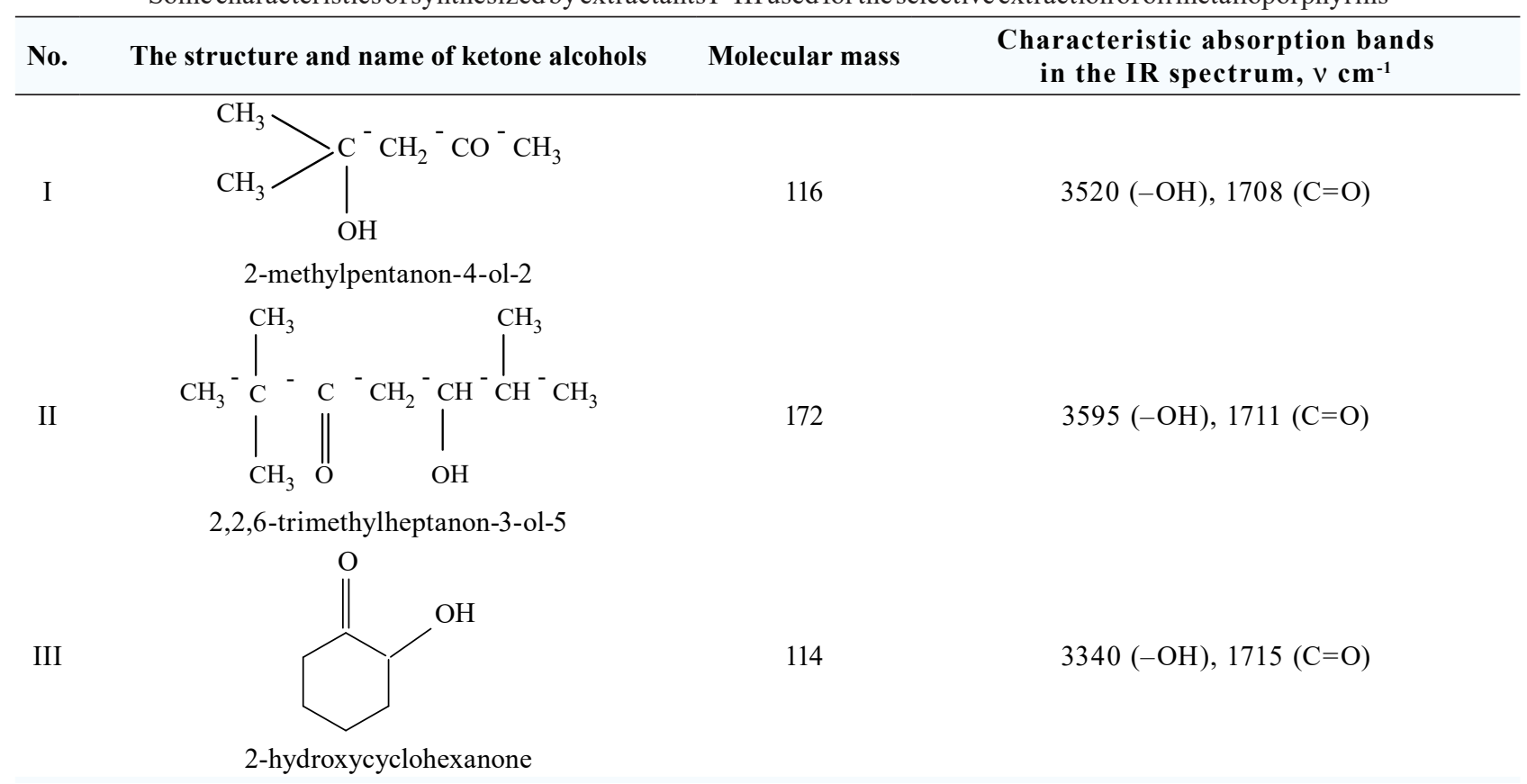




\section{Synthesis of bifunctional extractants (I-III).}

Samples of bifunctional ketone alcohols are synthesized as follows:

- Obtaining 2-methylpentanon-4-ol-2 (I).

$1 \mathrm{~mol}$ of acetone was placed in a $250 \mathrm{ml}$ round bottom flask with a Soxhlet stirrer and reflux condenser. The sleeve was filled to half with barium oxide, covering it with a lid on top. The flask was heated in a water bath. The end of the reaction was established by stopping the boiling of the liquid in a boiling water bath (30 hours), after which the contents of the flask after filtration were distilled in vacuum, boiling temperature $83{ }^{\circ} \mathrm{C} ; n_{D}^{20} 1.4235$. The product yield was $70 \%$;

- Obtaining 2,2,5-trimethylheptanon-3-ol-5 (II).

To magnesium shavings $(0.6 \mathrm{~mol})$ coated with $40 \mathrm{ml}$ of ether was added dropwise $0.5 \mathrm{~mol}$ of bromine pinacoline $[(\mathrm{CH} 3)$ 2-C-CO-CH2 Br] and 0.6 mol of methyl ethyl ketone in $160 \mathrm{ml}$ of ether. The reaction was initiated by the addition of a small amount of magnesium activated with methyl iodide. After the start of the reaction, $200 \mathrm{ml}$ of benzene was rapidly added with vigorous stirring. The mixture was boiled for another 1 hour, and then upon cooling, it was hydrolyzed with a calculated amount of hydrochloric acid in $200 \mathrm{ml}$ of water. The organic layer was washed with $100 \mathrm{ml}$ of water, then $200 \mathrm{ml}$ of $1 \mathrm{~N}$ sodium hydroxide was added with stirring over 1 hour to destroy the bromketone residues. After distillation, ketol was obtained with a yield of $66 \%$, boiling temperature $87-88^{\circ} \mathrm{C} ; n_{D}^{20} 1.4339$;

- Obtaining 2-hydroxycyclohexanone (III).

A solution of $10 \mathrm{~g}(0.102 \mathrm{~mol})$ of cyclohexene oxide and $0.12 \mathrm{ml}$ of boron trifluoride etherate in $40 \mathrm{ml}$ of dimethyl sulfoxyl (dimethyl sulfoxide prepared by azeotropic distillation with benzene) was heated in a steam bath for 22 hours. The catalyst was introduced into the reaction mass twice at 15 and 20 hours in the amount of $0.06 \mathrm{ml}$ and $0.04 \mathrm{ml}$, respectively. The reaction mixture was poured into ice water and extracted with chloroform. The extract was dried, the solvent (chloroform) was distilled off, 2-hydroxycyclohexanone was obtained from the residue, yield $76 \%$, boiling temperature $83-88^{\circ} \mathrm{C}$.

Asphaltenes extracted from heavy oil do not dissolve in extractants (I-III) at temperatures below $100^{\circ} \mathrm{C}$, however, at higher temperatures, the dissolution of oil in these extractants becomes noticeable. Unlike bifunctional extractants, monofunctional compounds, such as acetone, ethyl alcohol, DMF [18] dissolve oil quite noticeably. This makes it difficult to isolate pure metalloporphyrin concentrates. Due to the fact that bifunctional extractants do not dissolve oil and selectively extract metalloporphyrins from oil, it becomes possible to obtain oil metalloporphyrin concentrates in high yields. The results of these studies are given in Table 3.

Table 3

Solubility of asphaltenes extracted from heavy oil with extractants (I-III)

\begin{tabular}{ccccc}
\hline Extractants & \multicolumn{4}{c}{ Solubility, $\mathbf{~ m} / \mathbf{g}$} \\
\cline { 2 - 5 } 2-methylpentanon-4-ol-2 & $\mathbf{5 0}^{\circ} \mathbf{C}$ & $\mathbf{1 0 0}{ }^{\circ} \mathbf{C}$ & $\mathbf{1 2 0}^{\circ} \mathbf{C}$ & $\mathbf{1 4 0}{ }^{\circ} \mathbf{C}$ \\
\hline 2,2,6-trimethylheptanon-3-ol-5 (II) & - & - & 6.5 & 12 \\
2-hydroxycyclohexanone (III) & - & - & 5.8 & 9.6 \\
Acetone & - & - & 3.7 & 102 \\
Ethanol & 25 & 58 & 87 & 117 \\
DMF & 18 & 38 & 54 & 73
\end{tabular}

Table 4 contains results of the extraction of metalloporphyrins from asphaltenes with the introduction of extractants (I-III).

Fig. 1 shows the dependence of the degree of extraction of asphaltenes on the mass ratio of extractant/asphaltene. 
Table 4

The results of extraction chromatographic isolation of vanadyl and nickel porphyrins from asphaltenes with a mass ratio of extractant/asphaltene equal to 1:30

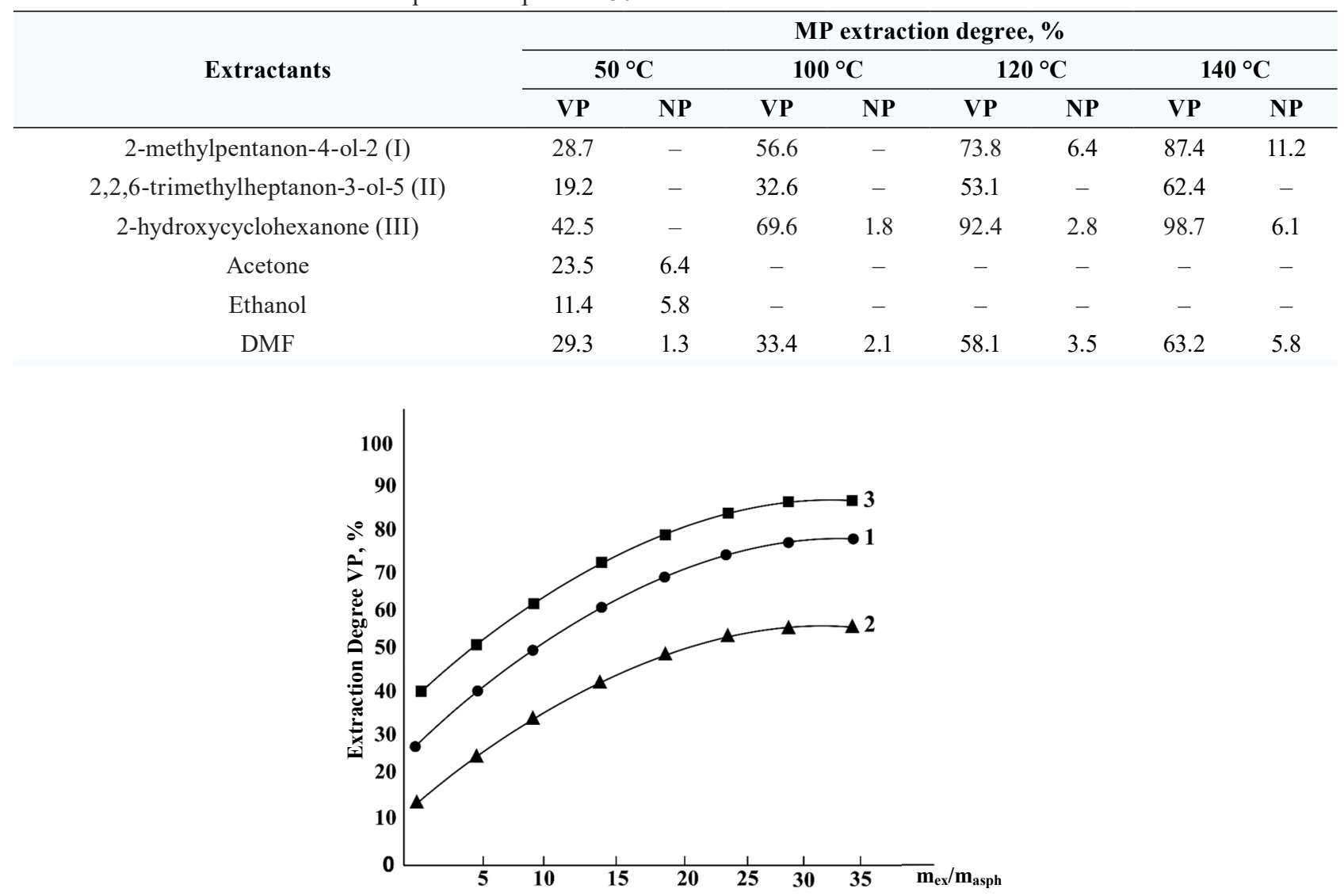

Fig. 1. The dependence of MP extraction degree from the mass ratio of extractant/asphaltene at $\mathrm{T}_{e x}=120^{\circ} \mathrm{C}: \bullet-$ diacetone alcohol;

$\boldsymbol{\Delta}$-2,2,5-trimethylheptanon-3-ol-5; - 2-hydroxycyclohexanone

A study of the influence of the ratio of the mass of extractant to the mass of asphaltene taken on the efficiency of extraction of natural metalloporphyrins showed that the degree of extraction of metalloporphyrins (MP) increases with an increase in this indicator. The most optimal results are obtained with a mass ratio of extractant to asphaltene equal to 1:30. A further increase in the ratio of extractant/asphaltene does not lead to a change in the extraction degree.

Synthesis of metalloporphyrin catalysts.

The porphyrin mixture isolated from oil residues can't be used as a catalyst for the oxygenation of hydrocarbons, since different metals direct the reaction by a different mechanism. In this regard, the mixture of metalloporphyrin complexes of oil was further subjected to the following transformations for the synthesis of target catalysts containing individual transition metals.

The following is a description of the synthesis of metal-individual metalloporphyrin complexes from porphyrin concentrate:

1. The oil porphyrin concentrate is demetallized by mixing it with a dilute hydrochloric acid solution (7-9\%). As a result of this treatment, oil metalloporphyrin complexes decompose into the corresponding porphyrin and metal ion, which passed into the aqueous layer. The first stage can be represented as follows:

$\mathrm{MP}+4 \mathrm{NX} \rightarrow\left[\mathrm{N}_{2} \mathrm{P}\right] \cdot 2 \mathrm{X}+\mathrm{MX}_{2}$, 
where $\left[\mathrm{N}_{2} \mathrm{P}\right]$ is a doubly charged porphyrin cation, MP-metalloporphyrin complex, $\mathrm{X}$-ion of chlorine $\left(\mathrm{Cl}^{-}\right)$.

Treatment with a hydrochloric acid solution was carried out until the characteristic absorption bands at $515 \mathrm{~nm}, 563 \mathrm{~nm}$ and $528 \mathrm{~nm}$ in ultraviolet radiation/species disappeared spectra, which indicates the complete decay of the oil metalloporphyrin complex.

2. The complex $\left[\mathrm{N}_{2} \mathrm{P}\right] \cdot 2 \mathrm{X}$ was neutralized with alkali to $\mathrm{pH}=6-8$ in order to obtain oil porphyrin:

$$
\left[\mathrm{N}_{2} \mathrm{P}\right] \cdot 2 \mathrm{X}+2 \mathrm{NaOH} \rightarrow \mathrm{P}+2 \mathrm{NaX}+2 \mathrm{H}_{2} \mathrm{O} .
$$

After neutralization, the reaction mass was washed with water until a neutral reaction was dried by azeotropic distillation with benzene. After removal of benzene, the oil porphyrin is distilled in a deep vacuum.

3. The isolated oil porphyrin was dissolved in benzene, and pre-prepared sodium phenyl in excess was added to the resulting solution. As a result of this reaction, the hydrogen atoms of two nitrogen of the porphyrin ring were replaced by sodium atoms according to the scheme:

$$
\mathrm{P}+2 \mathrm{PhNa} \rightarrow \mathrm{Na}_{2} \mathrm{P}+2 \mathrm{C}_{6} \mathrm{H}_{6},
$$

where $\mathrm{P}$ - a doubly charged porphyrin anion.

Next, the disodium derivative is treated in absolute alcohol with the acetate of the desired transition metal (Fe, Mn, Co, Ni). Moreover, almost with a quantitative yield, the corresponding individual metal complex is formed:

$$
\mathrm{Na}_{2} \mathrm{P}+\mathrm{M}\left(\mathrm{OCOCH}_{3}\right)_{2} \rightarrow \mathrm{PM}+2 \mathrm{CH}_{3} \mathrm{COONa} \text {. }
$$

After distillation of ethyl alcohol to $1 / 3$ of the volume, colored crystals of MP-metalloporphyrin complexes are separated from the solution upon standing. Isolated metalloporphyrins are characterized by IR spectra.

Table 5 shows the values of the melting temperature, yields and results of elemental analysis of the synthesized metalloporphyrins.

\section{Table 5}

Physico-chemical properties of synthesized metalloporphyrin catalysts

\begin{tabular}{cccccc}
\hline $\begin{array}{c}\text { Metallo- } \\
\text { porphyrins }\end{array}$ & Melting point, ${ }^{\circ} \mathbf{C}$ & Yield, $\%$ & \multicolumn{3}{c}{ Found, \% } \\
\cline { 4 - 6 } & 257 & 85 & 72.04 & H & N \\
\hline CoP & 261 & 87 & 71.63 & 6.68 & 10.39 \\
FeP & 283 & 90 & 71.65 & 6.71 & 10.57 \\
NiP & 271 & 42 & 71.6 & 8.10 & 10.39 \\
MnP & & & & & 12.30
\end{tabular}

\section{Discussion of results}

The research results (Table 4) indicate that the extractants I-III synthesized in this work are superior to the widely used extractants, such as acetone, ethyl alcohol, and DMF, in the extraction efficiency of metalloporphyrins.

When passing from 2-methyl-pentanon-4-ol-2 to 2-hydroxycyclohexanone, the degree of extraction increases sharply and the latter almost quantitatively extracts porphyrins at temperatures of $120-140^{\circ} \mathrm{C}$.

The metal porphyrins extracted from oil residues served as the basis for the synthesis of metal porphyrin complexes of iron $(\mathrm{FeP})$, cobalt $(\mathrm{CoP})$, nickel $(\mathrm{NiP})$ and manganese $(\mathrm{MnP})$. The formation of metalloporphyrin complexes (MP) as a result of these transformations was established using spectral data. In the IR spectra of metal porphyrins based on the oil porphyrin complex 
(OPC), characteristic bands were found that confirm the presence of the hemin ring. Thus, pyrrole fragments are characterized by absorption bands at vibrational frequencies of 1507, 1522, and $1608 \mathrm{~cm}^{-1}$. Absorption band at $856 \mathrm{~cm}^{-1}$ corresponds to non-planar deformation vibrations of the methine bridges of the porphyrin ring. The absorption band at $636 \mathrm{~cm}^{-1}$ corresponds to signals of non-planar deformation vibrations of the $=\mathrm{NH},-\mathrm{CN}$ and $\mathrm{C}=\mathrm{N}$ groups of the group are characterized by absorption bands at $1376 \mathrm{~cm}^{-1}$ and $1441 \mathrm{~cm}^{-1}$, respectively.

Table 6 contains spectral characteristics of synthesized metalloporphyrins.

Table 6

Spectral characteristics of synthesized oil metalloporphyrin complexes

\begin{tabular}{ccc}
\hline Metalloporphyrins & $\begin{array}{c}\text { Absorption bands in the electronic } \\
\text { spectrum maximum, nm }\end{array}$ & Absorption bands in the IR spectrum maximum, $\boldsymbol{v} \mathbf{c m}^{-\mathbf{1}}$ \\
\hline $\mathrm{CoP}$ & $417,533,551$ & $1507,1522,1608$ (p.r.), $856\left(\mathrm{CH}_{2}\right), 636(=\mathrm{NH})$ \\
$\mathrm{FeP}$ & $411,534,570$ & $1512,1520,1599$ (p.r.), $850\left(\mathrm{CH}_{2}\right), 634(=\mathrm{NH})$ \\
$\mathrm{NiP}$ & $405,520,556$ & $1503,1517,1602$ (p.r.) $847\left(\mathrm{CH}_{2}\right), 641(=\mathrm{NH})$ \\
$\mathrm{MnP}$ & $415,528,557$ & $1506,1512,1600$ (p.r.) $845\left(\mathrm{CH}_{2}\right), 639(=\mathrm{NH})$
\end{tabular}

Electronic absorption spectra in the ultraviolet and visible spectral ranges, oil porphyrin concentrate and metalloporphyrins are shown in Fig. 2. Let's note that the UV/species spectra of all oil metalloporphyrins are usually characterized by an intense Soret band $\left(\lambda_{\max } \sim 400 \mathrm{~nm}\right)$. In addition to this band, four so-called $Q$ low-intensity bands are observed in the electronic absorption spectra.

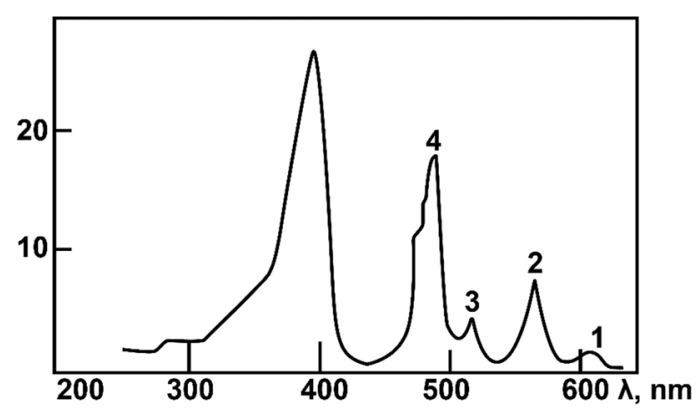

Fig. 2. Electronic absorption spectra of oil porphyrin in paraffin at a temperature of $25^{\circ} \mathrm{C}$ :

$1,2,3,4-$ absorption bands

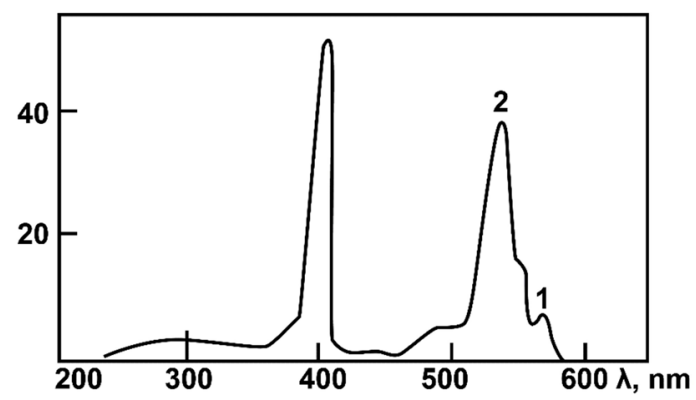

Fig. 3. Electronic absorption spectra of metalloporphyrin in paraffin at a temperature of $25^{\circ} \mathrm{C}$ :

1,2 - absorption bands

The spectrum of a solution of oil porphyrin in the visible region (Fig. 2) consists of four main absorption bands. A comparison with the spectrum of metal porphyrins by the example of metalloporphyrin (Fig. 3) shows that bands 1 and 3 are much more intense, and the intensity of band 2 is approximately the same as that of oil porphyrin. The introduction of an iron atom into the porphyrin ring leads to a narrowing of the Soret band. In addition, instead of four bands, 
two (1 and 2) bands are observed, with noticeably different intensities. It should be noted that the form of the electronic absorption spectra of porphyrins noticeably differs for different porphyrins and in different media [19-21].

In order to study the catalytic properties of the synthesized metalloporphyrin catalysts in the oxidation reaction of unsaturated hydrocarbons, their oxygen species were synthesized.

The scheme of oxygenation and the formation of the oxygen adduct is shown by the example of a cobalt porphyrin sample:

$$
2 \mathrm{PCo}^{\mathrm{II}}+\mathrm{O}_{2} \rightarrow \mathrm{PCo}^{\mathrm{III}}
$$

The infrared spectral data of the cobalt porphyrin complex and its dioxide adduct are shown in Fig. 4.

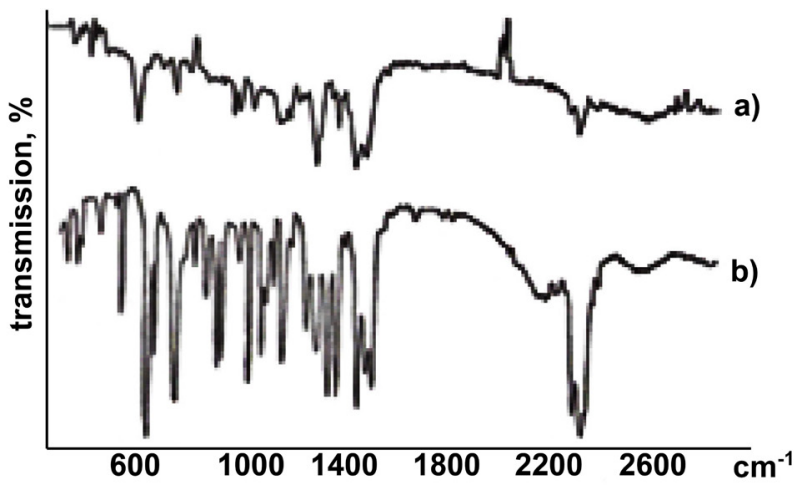

Fig. 4. IR spectra of metalloporphyrin complexes: $a$ - cobalt porphyrin complex, $b$ - adduct of cobalt porphyrin complex

The IR spectrum of the oxygen complex (2) Fig. 4 shows a characteristic absorption band at $1127 \mathrm{~cm}^{-1}$, confirming the presence of a oxygen fragment in complex (2). The IR spectra of both porphyrin complexes and their dioxide adducts are fairly well described in the literature [22, 23]. They indicate that the frequencies $v(\mathrm{O}-\mathrm{O})$, characteristic of complexes of transition ions with molecular oxygen, are found in the region of $1104-1226 \mathrm{~cm}^{-1}$. In this regard, it can be argued that the absorption band at $1127 \mathrm{~cm}^{-1}$ is formed during the interaction of molecular oxygen with metalloporphyrins and may be an indicator of the formation of dioxide adducts of metalloporphyrins with molecular oxygen.

When comparing the cobalt content in the complex compound (1) and the oxygen adduct (2), it was found that the molar ratio of the complex to molecular oxygen is $2: 1$.

An important feature of the dioxide adduct of the cobalt (II) oil porphyrin complex (2) is that such dioxide adducts epoxidize olefins [22, 23]. Thus, the previously prepared adduct (2) epoxidizes 1-pentene, forming 1,2-oxidopentane.

The totality of the obtained results allows to state that although the electron transfer from Co (II) to oxygen is completed completely, the obtained oxygen-oxygen adduct (2) can't be represented as a complex in which cobalt $(\mathrm{P})$ ion combines with singlet oxygen.

It should be noted that the oxygen dioxide anion $\left(\mathrm{O}_{2}^{2-}\right)$ in the complex compound (2) can't directly epoxidize the olefin, because $\mathrm{O}_{2}^{2-}$ anion is not electrophilic. An alternative mechanism for the epoxidation of alkenes with a dioxide adduct (2) allows the occurrence of oxinoid resonance structures A and B resulting from the decomposition of the cobalt (II) dioxide porphyrin complex (4):

$$
\mathrm{PCo}^{\mathrm{III}} \ldots \mathrm{O}-\mathrm{O} \ldots \mathrm{Co}^{\mathrm{III}} \mathrm{P} \rightarrow \mathrm{PCo}=\mathrm{O} \leftrightarrow \mathrm{PCo}^{+} \mathrm{O}^{-} .
$$

The formation of 1,2-oxidopentane is quite possible in the interaction of 1-pentene with an oxinoid resonance structure A having electrophilic oxygen according to the scheme (Fig. 5). 


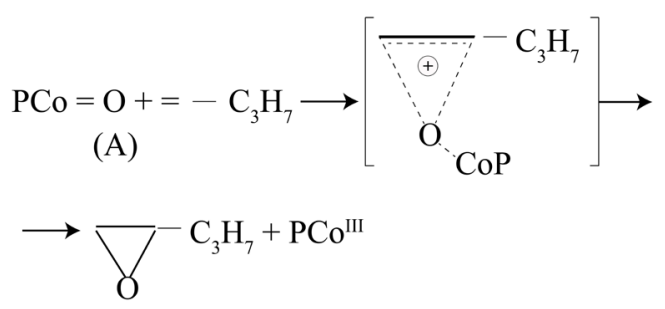

Fig. 5. Mechanism of 1,2-oxidopentane formation

The resulting 1,2-oxidopentane was identified by gas-liquid chromatography.

It turned out that during the oxidation of pentene- 1 in the presence of catalytic amounts of the considered oil metalloporphyrin complexes at room temperature, pentane oxide is formed in yields of $27-47 \%$. By a similar method, the epoxidation of trimethylene, cyclopentene, 1-methylcyclohexene and styrene was also carried out. The results of experimental data on the epoxidation of olefins by molecular oxygen in the presence of oil metalloporphyrins indicate the possibility of their use as eloxidizing catalysts.

\section{Conclusions}

1. A highly effective method for the separation of metalloporphyrin concentrate from heavy oils and oil products using highly selective bifunctional organic compounds (ketone alcohols) with respect to metal porphyrins has been developed. The synthesized bifunctional compounds are superior in the efficiency of extraction of metalloporphyrins in comparison with known extractants. The best results were shown by estrogen-2-hydroxycyclohexanone.

2. Based on the porphyrin concentrate isolated from heavy oil residues, individual oil porphyrin complexes $\mathrm{Mn}, \mathrm{Fe}, \mathrm{Co}$, and $\mathrm{Ni}$ were synthesized by a specially developed technique. The structure of the synthesized oil metalloporphyrin complexes and their oxygen species adducts were characterized by IR and electron spectroscopy.

3. The catalytic properties of the synthesized oil metalloporphyrin complexes were studied in the alkenes oxygenation reaction. An alternative mechanism for the epoxidation of alkenes by a dioxide adduct is considered, which allows the formation of oxinoid resonance structures.

\section{References}

[1] Len, Zh. M. (1998). Supramolekulyarnaya himiya: Kontseptsii i perspektivy. Novosibirsk: Nauka, 334.

[2] Groves, K., Lee, J. (2000). The porphyrin handbook. Vol. 4. Academic Press, 17-39.

[3] Suslick, K. S. (2000). The porphyrin handbook. Vol. 4. Academic Press, 41-63.

[4] Marchon, J.-C., Ramasseul, R. (2003). Chiral Metalloporphyrins and Their Use in Enantiocontrol. The Porphyrin Handbook, 75-132. doi: https://doi.org/10.1016/b978-0-08-092385-7.50009-4

[5] Sheldon, R. A. (Ed.) (1994). Metalloporphyrins in catalytic oxidation. Marcel Dekker Inc, 390.

[6] Barona-Castaño, J., Carmona-Vargas, C., Brocksom, T., de Oliveira, K. (2016). Porphyrins as Catalysts in Scalable Organic Reactions. Molecules, 21 (3), 310. doi: https://doi.org/10.3390/molecules21030310

[7] Lesage, S., Xu, H., Durham, L. (1993). The occurrence and roles of porphyrins in the environment: possible implications for bioremediation. Hydrological Sciences Journal, 38 (4), 343-354. doi: https://doi.org/10.1080/02626669309492679

[8] Imran, M., Ramzan, M., Qureshi, A., Khan, M., Tariq, M. (2018). Emerging Applications of Porphyrins and Metalloporphyrins in Biomedicine and Diagnostic Magnetic Resonance Imaging. Biosensors, 8 (4), 95. doi: https://doi.org/10.3390/ bios 8040095

[9] Meunier, B. (1992). Metalloporphyrins as versatile catalysts for oxidation reactions and oxidative DNA cleavage. Chemical Reviews, 92 (6), 1411-1456. doi: https://doi.org/10.1021/cr00014a008

[10] Achugasim, O., Ojinnaka, C., Osuji, L. (2013). Management of petroporphyrins in a crude oil polluted environment. European Chemical Bulletin, 2 (10), 794-796. doi: http://dx.doi.org/10.17628/ecb.2013.2.794-796

[11] García-Arellano, H., Buenrostro-Gonzalez, E., Vazquez-Duhalt, R. (2004). Biocatalytic transformation of petroporphyrins by chemical modified cytochrome C. Biotechnology and Bioengineering, 85 (7), 790-798. doi: https://doi.org/10.1002/bit.20023

[12] Maravin, G. B., Avdeev, M. V., Bagriy, E. I. (2000). Okislitel'naya funktsionalizatsiya nasyshchennyh uglevodorodov na metallokompleksnyh katalizatorah porfirinogo ryada. Neftehimiya, 40 (1). 
[13] Miralamov, G. F. (2005). Kataliticheskaya ochistka prirodnogo gaza i uglevodorodnyh gazovyh vybrosov neftehimicheskoy promyshlennosti ot serovodoroda. Neftehimiya, 45 (5), 397-399.

[14] Birnbaum, T., Hahn, T., Martin, C., Kortus, J., Fronk, M., Lungwitz, F. et. al. (2014). Optical and magneto-optical properties of metal phthalocyanine and metal porphyrin thin films. Journal of Physics: Condensed Matter, 26 (10), 104201. doi: https:// doi.org/10.1088/0953-8984/26/10/104201

[15] Freeman, D. H., O’Haver, T. C. (1990). Derivative spectrophotometry of petroporphyrins. Energy \& Fuels, 4 (6), $688-694$. doi: https://doi.org/10.1021/ef00024a012

[16] Agaguseynova, M. M., Abdullaeva, G. N., Salmanova, N. I. (2010). Supramolekulyarnye metalloporfirinovye kataliticheskie sistemy dlya neftehimicheskogo sinteza. Neftepererabotka i neftehimiya, 172-175.

[17] Serebryakov, A. O. (2012). Composition, properties and processing of oil azerbaijan caspian sea. Geologiya, geografiya i global'naya energiya, 3 (46).

[18] Milordov, D. V. (2013). Sopostavitel'niy analiz ekstraktsionnyh metodov vydeleniya porfirinov iz asfal'tenov tyazheloy nefti. Himiya i tehnologiya topliv i masel, 3, 29-33.

[19] Alben, J. O. (1978). Infrared Spectroscopy of Porphyrins. The Porphyrins, 323-345. doi: https://doi.org/10.1016/b978-0-12220103-5.50014-3

[20] Kitagawa, T., Ozaki, Y. (2005). Infrared and Raman spectra of metalloporphyrins. Metal Complexes with Tetrapyrrole Ligands I, 71-114. doi: https://doi.org/10.1007/bfb0036790

[21] Al-Shewiki, R. K., Mende, C., Buschbeck, R., Siles, P. F., Schmidt, O. G., Rüffer, T., Lang, H. (2017). Synthesis, spectroscopic characterization and thermogravimetric analysis of two series of substituted (metallo)tetraphenylporphyrins. Beilstein Journal of Nanotechnology, 8, 1191-1204. doi: https://doi.org/10.3762/bjnano.8.121

[22] Simándi, L. I. (1992). Catalytic Activation of Dioxygen by Metal Complexes. Catalysis by Metal Complexes. doi: https:// doi.org/10.1007/978-94-011-2850-6

[23] Sun, Y., Hu, X., Li, H., Jalbout, A. F. (2009). Metalloporphyrin-Dioxygen Interactions and the Effects of Neutral Axial Ligands. The Journal of Physical Chemistry C, 113 (32), 14316-14323. doi: https://doi.org/10.1021/jp901620a

Received date 25.04.2020

Accepted date 24.06.2020

Published date 31.07.2020
(C) The Author(s) 2020

This is an open access article under the CC BY license (http://creativecommons.org/licenses/by/4.0). 